\title{
A case of blindness associated with myocardial infarction
}

\author{
R. P. BRettle \\ M.B., Ch.B., M.R.C.P. \\ Walsgrave Hospital, Coventry
}

\begin{abstract}
Summary
A patient presented to hospital with sudden onset of blindness which was subsequently shown both clinically and by radionucleotide scanning to be cortical in nature. Four days before admission he had suffered 2 short episodes of aching jaw, dizziness, and profuse sweating. Myocardial infarction was confirmed by serial ECGs and cardiac enzymes. His cortical blindness was thought to be secondary to an embolus from a myocardial mural thrombus.

$A$ review of the literature revealed 5 previous patients with cortical blindness and associated myocardial infarction. In 2 of these, blindness followed within days of the myocardial infarct, but in none was it the presenting feature of a myocardial infarct.
\end{abstract}

\section{Introduction}

Cortical blindness is characterized by bilateral loss of vision with normal pupillary reflexes and normal fundal appearances. Associated features are denial of blindness and spatial disorientation (Anton, 1899).

A previous review of the literature by Symonds and Mackenzie (1957) revealed 2 cases out of 51 associated with myocardial infarction; in one, blindness followed a few days after the myocardial infarction, and in the other there was an interval of 3 years. They collected a further 9 cases, 3 of which were associated with myocardial infarction; one patient had severe chest pain 3 days before the onset of blindness, whilst the others had past histories of myocardial infarcts. In all these cases the diagnosis of myocardial infarction was made before that of cortical blindness.

\section{Case history}

A 57-year-old machinist was admitted to hospital complaining of loss of vision. The day before he had fallen off his chair and, although he remained conscious, he was slightly confused and had difficulty recognizing family and friends. He retired to bed and on wakening that evening was apparently blind. Direct questioning revealed that 4 days before his admission he had had 2 episodes, lasting $20 \mathrm{~min}$ each, of an aching jaw associated with profuse sweating, nausea and a feeling of faintness.

On admission he was alert and co-operative. He was able to perceive light only with the right eye and was blind in the left. The optic fundi were normal, the pupils reacted to light, and eye movements were full. The rest of the neurological examination was normal except for an extensor left plantar response. $\mathrm{He}$ had a BP of $150 / 90 \mathrm{mmHg}$ and was in sinus rhythm. There were no carotid or vertebral bruits.

The clinical diagnosis was of myocardial infarct complicated by cortical blindness. Serial ECGs showed an acute full thickness septal infarct. The initial lactate dehydrogenase level was 930 i.u. but fell to normal levels over the next 7 days. X-rays of skull and chest, full blood count, electrolytes, urea and ANF were all normal. His initial ESR was $55 \mathrm{~mm} / \mathrm{hr}$ but 4 days later it had fallen to $26 \mathrm{~mm} / \mathrm{hr}$. Examination of the CSF revealed a protein of $0.72 \mathrm{~g} / \mathrm{l}$ with no cells. A radionucleotide brain scan showed 2 areas of increased emission in the right and left parieto-temporal regions. The right lesion was more extensive than the left (Fig. 1(a)).

His eyesight improved initially to a corrected visual acuity of $6 / 18$ on the right and 6/60 on the left. At this stage he had a left humonymous hemianopia with no evidence of macular sparing reflecting the predominance of the right-sided lesion and involvement of the posterior cerebral arteries. His eyesight continued to improve until 8 months later there was no field defect and visual acuity was $6 / 12$, N6 on the right, 6/9, N24 on the left. He had returned to work but needed to be taken to and from work because of a tendency to get lost. He had also noted some difficulty in concentrating, and scanning print. A repeat brain scan showed resolution on the left and a smaller lesion on the right (Fig. 1(b)). 


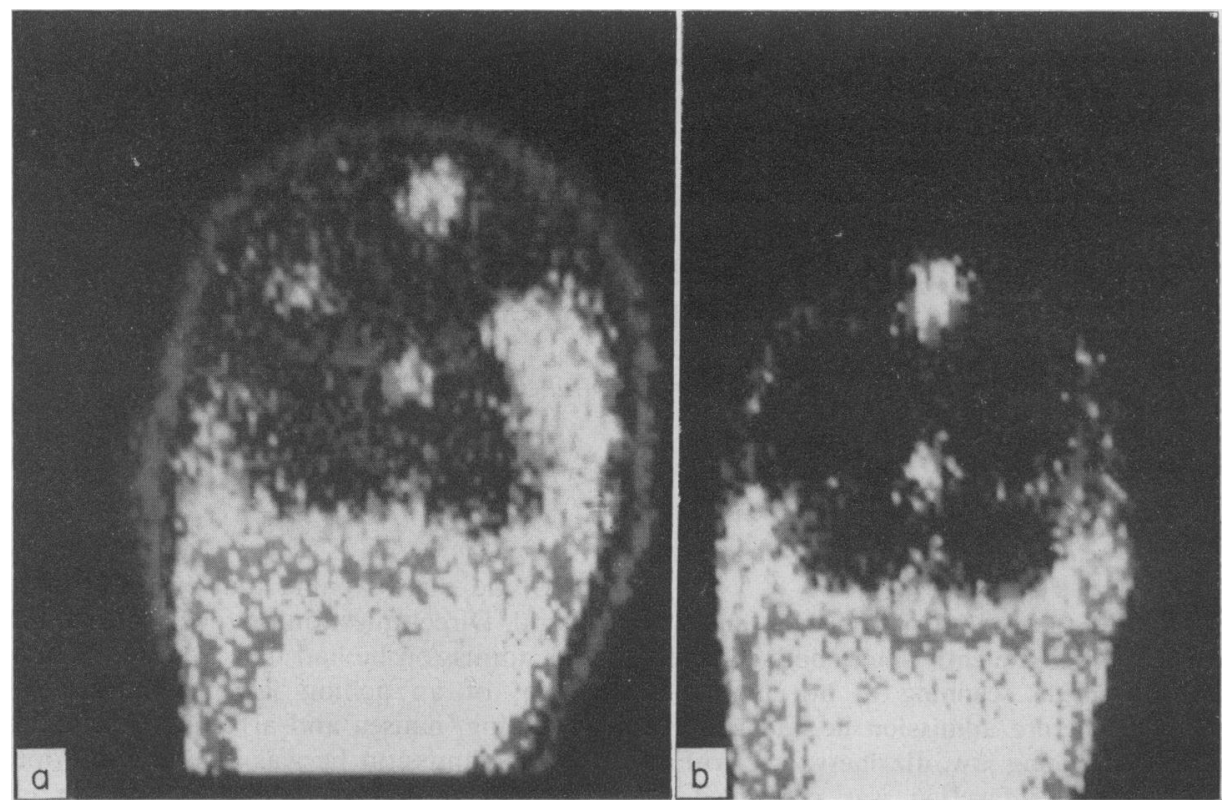

FIG. 1. Radionucleotide brain-scan at presentation (a) and after 8 months (b), showing initially bilateral areas of increased emission greater on the right, and later partial resolution consistent with infarction.

\section{Discussion}

Symonds and Mackenzie (1957) in discussing the pathogenesis of cortical blindness concluded that in general it was due to embolism; emboli anywhere from the heart to the basilar artery pass up the basilar artery and fragment to involve both posterior cerebral arteries. Cortical blindness then results from damage to both the occipital lobes, and this was demonstrated in the present case both clinically and by radionucleotide brain scanning. From postmortem studies the incidence of cerebral infarcts associated with emboli originating from the heart has been recently estimated at $40-50 \%$ (Blackwood et al., 1969; Torvik and Jorgensen, 1964). However, this association is often clinically overlooked. In a retrospective series of 1000 consecutive unselected post-mortems (Dozzi, 1937) there were 41 cases with established myocardial infarcts and $12(29 \%)$ of these were associated with a cerebral thrombosis or embolism. Dozzi also noted that in $10(24 \%)$ of these cases the cardiac lesion was clinically unsuspected and only found at post-mortem.

This case serves to underline Dozzi's assertion that myocardial infarction may present neurologically and that the association between myocardial ing farction and cerebrovascular lesions is unde्ध. estimated. Without such a striking presentatiơn, the underlying cause of this man's 'stroke' might have been overlooked and attributed to cerebral $\frac{\mathrm{O}}{\mathrm{Q}}$ arteriosclerosis.

\section{Acknowledgment}

I would like to thank Dr D. Riddoch for permission to publish this case and for his help in preparing the draft.

\section{References}

Anton, G. (1899) Ueber die Selbstwahrnehmung der Herderkrankungen des Gehirns durch den Kranken bei Rinden- $\frac{\sigma}{3}$ blindheit und Rindentautheit. Archives of Psychiatry, 84, 3286.

BlaCKWOOD, G., HallPike, J.F., Kocen, R.S. \& MaIR, W.G.P. (1969) Atheromatous disease of the carotid arterial system and embolism from the heart in cerebral 음 infarction: A morbid anatomical study. Brain, 92, 897.

DozzI, D.L. (1937) Cerebral embolism as a complication of coronary thrombosis. American Journal of Medical
Science, 194, 824.

SymondS, C. \& MACKenzie, I. (1957) Bilateral loss of vision from cerebral infarction. Brain, 80, 415 .

ToRviK, A. \& JoRgensen, L. (1964) Thrombotic and embolic N occlusions of the carotid arteries in an autopsy material. $\sigma$ Journal of the Neurological Sciences, 1, 24.

.

